\title{
Retinoic acid receptor expression vector inhibits differentiation of F9 embryonal carcinoma cells
}

\author{
Amy S. Espeseth, Shawn P. Murphy, and Elwood Linney ${ }^{1}$ \\ Department of Microbiology and Immunology, Duke University Medical Center, North Carolina 27710 USA
}

\begin{abstract}
Expression vectors have been constructed for a region of the human retinoic acid receptor-alpha (hRAR-alpha) and transferred into F9 embryonal carcinoma (EC) cells. When the vectors are overexpressed in F9 cells, clones can be selected for resistance to retinoic acid-induced differentiation. This effect is obtained even when the hRAR-alpha region is expressed as a $\beta$-galactosidase fusion protein. Using the $\beta$-galactosidase component of the fusion protein as a marker, overexpression of the fusion protein has been correlated with the retinoic acidresistance effect. The clones resistant to retinoic acid no longer exhibit the normal retinoic acid induction of endo B cytokeratin, laminin B-1, and tissue plasminogen activator mRNAs observed with normal F9 cells. Retinoic acid induction of type IV alpha-1 collagen and Hox-1.3 RNAs is observed with these clones. When transfected with a thyroid receptor DNA-binding sequence (TRE)/thymidine kinase promoter/luciferase construct, the retinoic acid-resistant clones do not yield the same retinoic acid-induced level of luciferase obtained with F9 cells. It is hypothesized that the RAR vectors are interfering with endogenous RAR(s) in a dominant-negative manner to inhibit retinoic acid-induced differentiation of F9 EC cells.
\end{abstract}

[Key Words: Embryonal carcinoma; retinoic acid receptor; differentiation]

Received July 19, 1989; revised version accepted September 4, 1989.

Retinoids have been shown to have dramatic effects on differentiation, development, and teratogenesis (for reviews, see Sporn et al. 1984; Nugent and Clark 1985; Sherman 1986). The mechanisms and effector molecules through which the retinoids mediate their effects are not yet known. Specific binding proteins for retinol /vitamin A) and retinoic acid have been isolated from variety of cell types [cellular retinol-binding protein (CRBP) and cellular retinoic acid-binding protein (CRABP); for review, see Chytil and Ong in Sporn et al. 1984]. Although these proteins are present in retinoic acid-responsive tissue, a function for CRBP and CRABP has yet to be found. Recently, another class of retinoic acid-binding proteins have been identified: steroid receptor-like retinoic acid receptor (RAR) molecules. Two different RARs in human cells have been described-hRAR-alpha (Giguere et al. 1987; Petkovich et al. 1987) and hRAR-beta (de The et al. 1987; Brand et al. 1988) or hRAR-epsilon (Benbrook et al. 1988)-as well as three mouse RARs (Zelent et al. 1989)-mRAR-alpha, mRAR-beta, and mRAR-gamma. The receptor proteins have distinct domains, A, B, C, D, E, and F, similar to steroid receptors. These include a zinc finger domain $|C|$, presumably responsible for DNA-binding specificity, and a region towards the carboxyl end $(E)$ for retinoic acid binding. The

${ }^{1}$ Corresponding author. homology between the DNA-binding domains of hRARalpha and hRAR-beta is $97 \%$ (Benbrook et al. 1988; Brand et al. 1988) and 95\% for the three mouse RARs (Zelent et al. 1989). The DNA-binding domains of the RARs have been replaced with the DNA-binding domains of either the estrogen (Petkovich et al. 1987; Benbrook et al. 1988; Brand et al. 1988) or glucocortocoid receptors (Giguere et al. 1987) to form chimeric receptors, which conveyed retinoic acid inducibility to sequences normally responsive to estrogen or glucocorticoids, respectively. Recently, it has been shown that hRAR-alpha responds to the same DNA sequences to which the thyroid receptor responds (TRE sequences, Umesono et al. 1988), and this has been confirmed for all three mRARs (Zelent et al. 1989). Therefore, these RARs are a subgroup of a superfamily of receptors, which include steroid receptors, thyroid receptors, and RARs (Evans 1988).

The F9 embryonal carcinoma (EC) cell culture system is distinctly affected by retinoic acid. Strickland and Mahdavi (1978) have shown that retinoic acid causes F9 EC cells to differentiate to parietal endoderm. Retinoic acid induces both a change in morphology and the differential expression of many different gene products (for examples, see Silver et al. 1983). Although these events may be mediated through more than one type of effector molecule, the parallels in structure between the RARs and known transcriptional activators, steroid receptors, 
suggest that RARs may play a major role in these processes.

If the RARs were responsible for the retinoic acid-induced differentiation of F9 cells, gene transfer of expression vectors for selected regions of RARs might be used to demonstrate this function. One approach would be to construct RAR expression vectors that would inhibit the function of endogenous RARs /dominant-negative approach). Alternatively, expression vectors could be designed that would be active in the absence of retinoic acid (constitutively active receptor). If RARs were responsible for retinoic acid induction of F9 cell differentiation, a receptor that inhibited the differentiation process could yield EC cell colonies resistant to retinoic acid that could be studied and characterized as individual cell lines; a constitutively active receptor would produce differentiated cells that could not be maintained as cell lines.

This paper describes vectors that appear to function via dominant-negative (Herskowitz 1987) interference with an endogenous RAR or RARs. Through overexpression of these vectors in F9 EC cells, clones that are resistant to retinoic acid-induced differentiation have been isolated. Although retinoic acid-induced F9 cells do not proliferate, these clones continue to grow with EC cell morphology. Retinoic acid administration to the clones does not produce the normal induction of laminin B-1, tissue plasminogen activator $(\mathrm{t}-\mathrm{PA})$, and endo $\mathrm{B}$ cytokeratin mRNAs, although induction of Hox-1.3 and type IV alpha-1 collagen mRNAs is observed. Transfection experiments with a TRE/thymidine kinase promoter/luciferase (TRE/TKpr/Luciferase) construct does not yield the normal retinoic acid induction of luciferase observed in F9 EC cells. Therefore, RARs have been implicated in the retinoic acid-induced differentiation of F9 cells.

\section{Results}

The basic vector used for gene transfer experiments in F9 EC cells was pHbetaApr-1 neo (Gunning et al. 1987). This vector has an SVNEO cassette for G418 selection and a $\beta$-actin promoter for expression of a second gene. When F9 cells are transfected with this vector, only a fraction of those selected for G418 resistance also express the nonselected gene. For this reason, the vector was modified by inserting a collagen linker/bacterial $\beta$ galactosidase cassette $(-\mathrm{CB})$ into the pHbetaApr-1 neo vector to allow the formation of fusion proteins with $\beta$ galactosidase at the carboxyl end (Germino and Bastia 1984). The vector pHbetaApr-1 neo-CB-17 is illustrated in Figure 1. Through the use of this vector, G418-resistant colonies can easily be screened for fusion protein synthesis by staining for $\beta$-galactosidase activity. The gene to be expressed from the $\beta$-actin promoter must be modified by removing its translational stop signal and by altering the joining region to place it in translational register with the collagen linker/ $\beta$-galactosidase component. If there are no collagenase cleavage sites in the protein, it can be separated from the -CB component after collagenase cleavage of the fusion protein (Germino and Bastia 1984).

Using the system described above, the SAC RAR-CB vector (Fig. 2) was constructed. The hRAR-alpha insert in this vector spans the start codon through the $S a c I$ site of the coding region (domains A, B, C, and including up to amino acid 189 in D). This site is $3^{\prime}$ to the DNAbinding domain $(\mathrm{C})$ of the receptor. Based on results with the thyroid hormone receptor, the hRAR-alpha insert in the SAC RAR-CB fusion protein might be expected to bind DNA sequences to which the hRAR-alpha receptor binds. Reports with the glucocortocoid receptor have shown that a small amount of transcriptional activation can be obtained from truncated forms of these receptors that are missing the steroid-binding domain (Godowski et al. 1987; Hollenberg et al. 1987). However, the transcriptional activation domain(s) of steroid receptors may also include a region of the steroid (ligand)-binding region, domain E (Gronemeyer et al. 1987; Hollenberg et al. 1987; Kumar et al. 1987; Godowski et al. 1988; Hollenberg and Evans 1988; Webster et al. 1988). The hRAR-alpha insert in this vector does not include the retinoic acid (ligand)-binding domain (E). If there are parallels in the functional domains of the RARs and the steroid receptors, this vector might produce a weak, constitutive activator of RAR target genes. Alternatively, if this particular region of the hRAR-alpha does not tran-

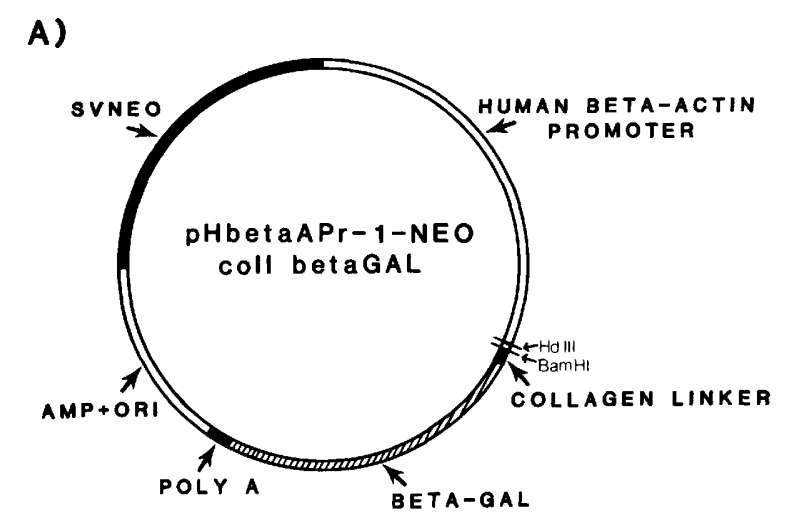

B)

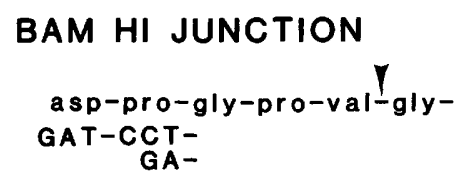

Figure 1. (A) Diagram of the modified pHbetaApr-1 neo vector of Gunning et al. (1987). A collagen linker/bacterial $\beta$-galactosidase cassette from Germino and Bastia (1984) was introduced into the vector as a $B a m H I\left(5^{\prime}\right)$ to $B g l I I\left(3^{\prime}\right)$ insert. This provides for insertion of a gene $5^{\prime}$ to the collagen linker/ $\beta$-galactosidase (-CB) cassette. The $3^{\prime}$ end of the gene must be modified for ligation to the $B a m H I$ site and to place it in translational register with the $-\mathrm{CB}$ cassette. This junction region is illustrated in $B$. The arrowhead represents the collagenase cleavage site for the linker. Therefore, if the fusion protein is cleaved, the gene has five additional amino acids attached to its carboxyl end. 

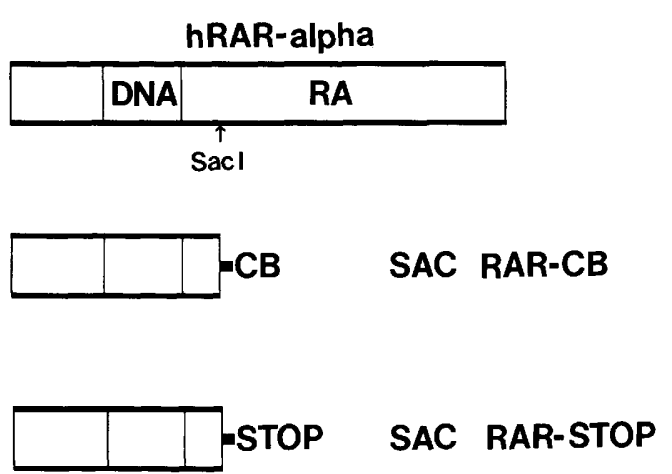

Figure 2. Diagram of the region of the hRAR-alpha cDNA, which was recombined into the $\mathrm{pHbetaApr-1}$ neo-CB-17 vector described in Fig. 1 to construct the SAC RAR-CB and SAC RAR-STOP vectors. The sequences between the start codon and 3 ' to the DNA-binding domain are contained in the vectors.

scriptionally activate retinoic acid-responsive genes and is expressed at high levels, it might be an effective inhibitor of the endogenous, activated RAR(s). When F9 cells expressing this vector are examined for $\beta$-galactosidase activity, most of the fusion protein is localized to the nucleus (Fig. 3A). In addition, the morphology of these cells remains EC-like (Fig. 3B). Therefore, if the RARs are involved in retinoic acid-induced differentiation, this particular vector is not functioning as a constitutive activator of differentiation.

Expression of the SAC RAR-CB vector did not affect the morphology of the transfected F9 EC cells (Fig. 3B).
The DNA-binding domain-containing fusion protein was also localized to the nucleus (Fig. 3A). In addition, the homology between the DNA-binding domains of the hRAR-alpha and -beta receptors suggested that the SAC RAR-CB fusion protein might be able to bind to the same DNA sequences to which these receptors bind. For these reasons, experiments were designed to examine whether overexpression of the fusion protein might interfere with retinoic acid-induced differentiation of F9 cells. SAC RAR-CB-transfected, G418-resistant colonies were treated with retinoic acid $\left(5 \times 10^{-7} \mathrm{M}\right)$ to determine whether expression of fusion protein might interfere with retinoic acid-induced differentiation. Mixed colonies of F9 cells selected for G418 resistance were plated at $10^{5}$ cells $/ 10-\mathrm{cm}$ plate and allowed to attach, and retinoic acid was applied. After 2 weeks, $\sim 30-50$ EC-like colonies per plate were obtained (no such colonies were obtained from non-G418-selected non-SAC RAR-CB cells). All of these EC-like colonies were positive for $\beta$-galactosidase activity, suggesting that presence of the fusion protein was necessary for the inhibition of retinoic acid-induced differentiation. For more efficient recovery of colonies, conditions were then developed for retinoic acid selection directly on the transfection plates (data not shown) with similar results.

Table 1 illustrates the results of several transfections of the SAC RAR-CB vector on F9 cells, the number of G418-resistant colonies obtained, and the number of G418/retinoic acid-resistant colonies obtained. To test the effect of the -CB component on the retinoic acid-resistant effect, a vector, SAC RAR-STOP was constructed, which has an artificial translational stop just $3^{\prime}$
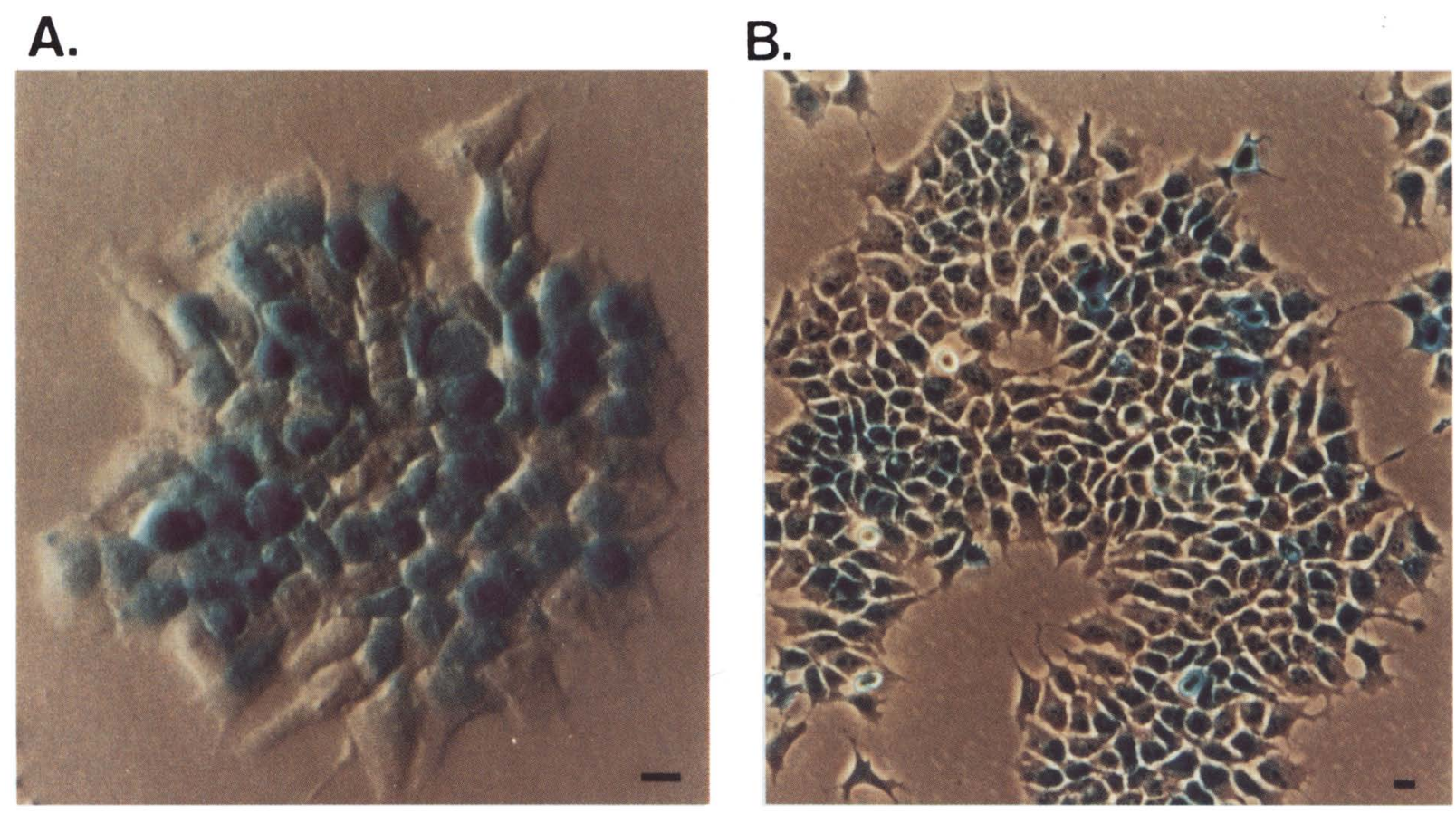

Figure 3. Photomicrographs of fixed F9 EC cells transfected with the SAC RAR-CB vector and selected for both G418 resistance and retinoic acid resistance. (A)X-gal-stained cells indicating localization of the fusion protein in the nucleus of the cells (Hoffman optics). (B) Phase micrograph of typical morphology of the clones. Bar (lower right), $15 \mu \mathrm{m}$. 
Table 1. Selection of $F 9$ colonies after transfection with the $S A C R A R-C B$ and SAC RAR-STOP vectors

\begin{tabular}{lccc}
\hline & \multicolumn{3}{c}{ EC-Like colonies (per two PLATES) } \\
\cline { 2 - 4 } Vector & G418 $^{\mathrm{r}}$ & $\mathrm{G}^{2} 18^{\mathrm{r}}$ and RA & RA $^{\mathrm{r}}(\%)$ \\
\hline Experiment 1 & & & \\
SAC RAR-CB & 940 & 32 & 3.4 \\
SAC RAR-STOP & 1492 & 45 & 3.0 \\
Experiment 2 & & & \\
SAC RAR-CB & 2848 & 59 & 2.0 \\
SAC RAR-STOP & 3880 & 151 & 3.9 \\
\hline
\end{tabular}

In each experiment four plates of F9 EC cells were each transfected with $20 \mu \mathrm{g}$ of the appropriate vector DNA. Two plates were selected with $800 \mu \mathrm{g} / \mathrm{ml}$ of G418 (G418 column) and two plates were selected with G418 and $5 \times 10^{-7} \mathrm{M}$ retinoic acid (RA) (G418 and RA RA $^{\mathrm{r}}$ column). After 14 days of retinoic acid selection, the plates were fixed and stained for $\beta$-galactosidase activity and the colonies counted.

to the SacI site (for details, see Material and methods). The -CB cassette is not in this vector; therefore, no fusion protein is produced. Table 1 shows that similar percentages of G418-/retinoic acid-resistant colonies are obtained with this vector, indicating that the effect is not due to the $-\mathrm{CB}$ component of the vector. That this effect is specific to these hRAR sequences is confirmed by our not obtaining retinoic acid-resistant, EC-like cells when F9 cells are transfected with and express at comparable levels a - $\mathrm{CB}$ fusion protein containing amino acids 1-448 of the 462 amino acids in the hRAR-alpha receptor or several specific subfragments of the SAC RAR$\mathrm{CB}$ receptor insert (E. Linney and A. Espeseth, unpubl.). We have evidence that these subfragment-encoded fusion proteins do not localize to the nucleus /data not shown). Thus, the minimal genetic information in the SAC RAR insert of the SAC RAR-CB or SAC RAR-STOP vectors required for the retinoic acid-resistant phenotype will require detailed mapping of the domains of the receptor.

One functionally convenient aspect of the pHbetaApr1 neo-CB-17 vector is that colonies expressing varying amounts of fusion proteins can easily be isolated. We routinely isolated 10 clones, plate them on duplicate plates, and then process one duplicate set for in situ staining for $\beta$-galactosidase activity. The in situ activity of clones varies and the intensity of staining correlates with amount of fusion protein determined by Western gel analysis, using a monoclonal antibody to $\beta$-galactosidase. Therefore, if a particular fusion protein appears to be affecting cells in a unique way, one has the option of examining whether the amount of fusion protein produced by a particular clone correlates with the phenomenon being observed.

As can be seen in Table 1, only a small percentage of G418-resistant colonies are also retinoic acid-resistant. The growing, EC-like, retinoic acid-resistant colonies strongly express the fusion protein, as indicated by in situ staining, suggesting that the differentiation defect may be due to overexpression of the fusion protein. To examine whether the retinoic acid-resistance effect cor- relates with overexpression of the fusion protein, Western blot analysis was performed to compare the amount of fusion protein in mixed colonies of SAC RAR-CB-transfected, G418-resistant cells with single clones of G418\%/retinoic acid-resistant cells (Fig. 4). Protein extracts of the mixed colonies and of clones 2 and $\mathrm{H}$ were electrophoresed on $5 \%$ polyacrylamide gels, and standard Western protocols were followed using a monoclonal antibody to $\beta$-galactosidase (see Materials and methods|. The $\beta$-galactosidase standards are in Figure 4 , lanes $A(4 \mathrm{ng})$ and $B(0.4 \mathrm{ng})$. Protein extracts from two SAC RAR-CB G418-/retinoic acid-resistant colonies were run [clone $\mathrm{H}$, lanes $\mathrm{C}, \mathrm{D}$, and $\mathrm{E}\{5 \mu \mathrm{g}, 10 \mu \mathrm{g}$, and 25 $\mu \mathrm{g}$ of protein, respectively); clone 2 , lanes $F, G$, and $\mathrm{H}(5$ $\mu \mathrm{g}, 10 \mu \mathrm{g}$, and $25 \mu \mathrm{g}$ of protein, respectively)]. Protein from mixed clones of SAC RAR-CB-transfected cells that were only selected for G418 resistance are in lanes I and $\mathrm{J} \mid 25 \mu \mathrm{g}$ and $200 \mu \mathrm{g}$, respectively). Protein was only barely detectable in lanes I and J, even when $200 \mu \mathrm{g}$ of protein was analyzed on the gel. A comparable amount of reaction could be shown in the retinoic acid-selected clones when only $5-10 \mu \mathrm{g}$ of protein was loaded on the gel (Fig. 4, lanes C, F, and G). Therefore, there is a 20- to 40-fold greater amount of fusion protein present in the G418-/retinoic acid-resistant clones. Comparing the amount of fusion protein in the G418-selected/retinoic acid-resistant clones to the $\beta$-galactosidase standards (lanes A and B) reveals that $25 \mu \mathrm{g}$ of total cellular protein from these clones contains $>4 \mathrm{ng}$ of fusion protein (Fig. 4, lanes $\mathrm{A}$ and $\mathrm{H}$ ). The 20- to 40 -fold difference in fusion protein expression between colonies that were and were not selected in the presence of retinoic acid suggests that

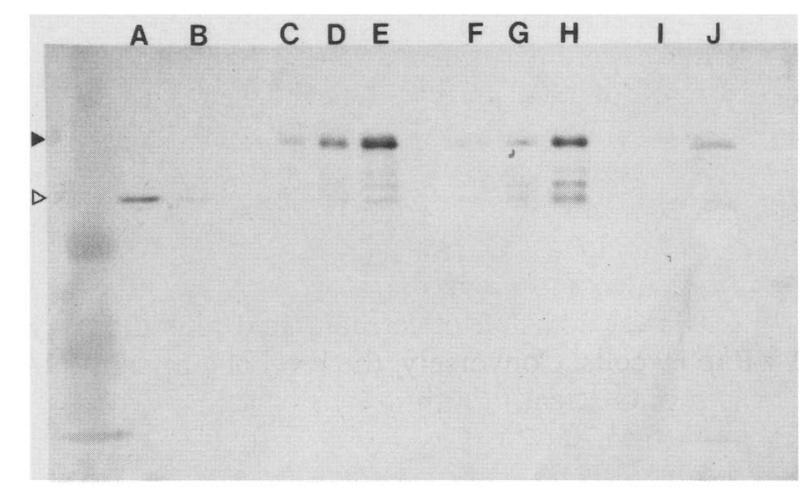

Figure 4. Western blot analysis of the fusion protein from SAC RAR-CB-transfected F9 EC cells. The quantity of fusion protein in individual SAC RAR-CB G418-/retinoic acid-resistant clones was compared with that in mixed colonies of SAC RAR-CBtransfected, G418-resistant cells. Total protein extracts were run on a $5 \%$ SDS-polyacrylamide gel, and standard Western blot protocols were followed using a monoclonal antibody against $\beta$-galactosidase. (Lanes $A$ and $B$ ) 4 and $0.4 \mathrm{ng}$ of control $\beta$-galactosidase protein. (Lanes $C-E$ ) G418-/retinoic acid-resistant clone $\mathrm{H}(5,10$, and $25 \mu \mathrm{g}$, respectively). (Lanes $F-H)$ G418-/retinoic acid-resistant clone 215,10 , and $25 \mu \mathrm{g}$, respectively). (Lanes $I$ and $I$ ) G418-resistant, mixed colonies (25 and $200 \mu \mathrm{g}$, respectively). (Solid arrowhead) Position of fusion protein; (open arrowhead) position of $\beta$-galactosidase. 

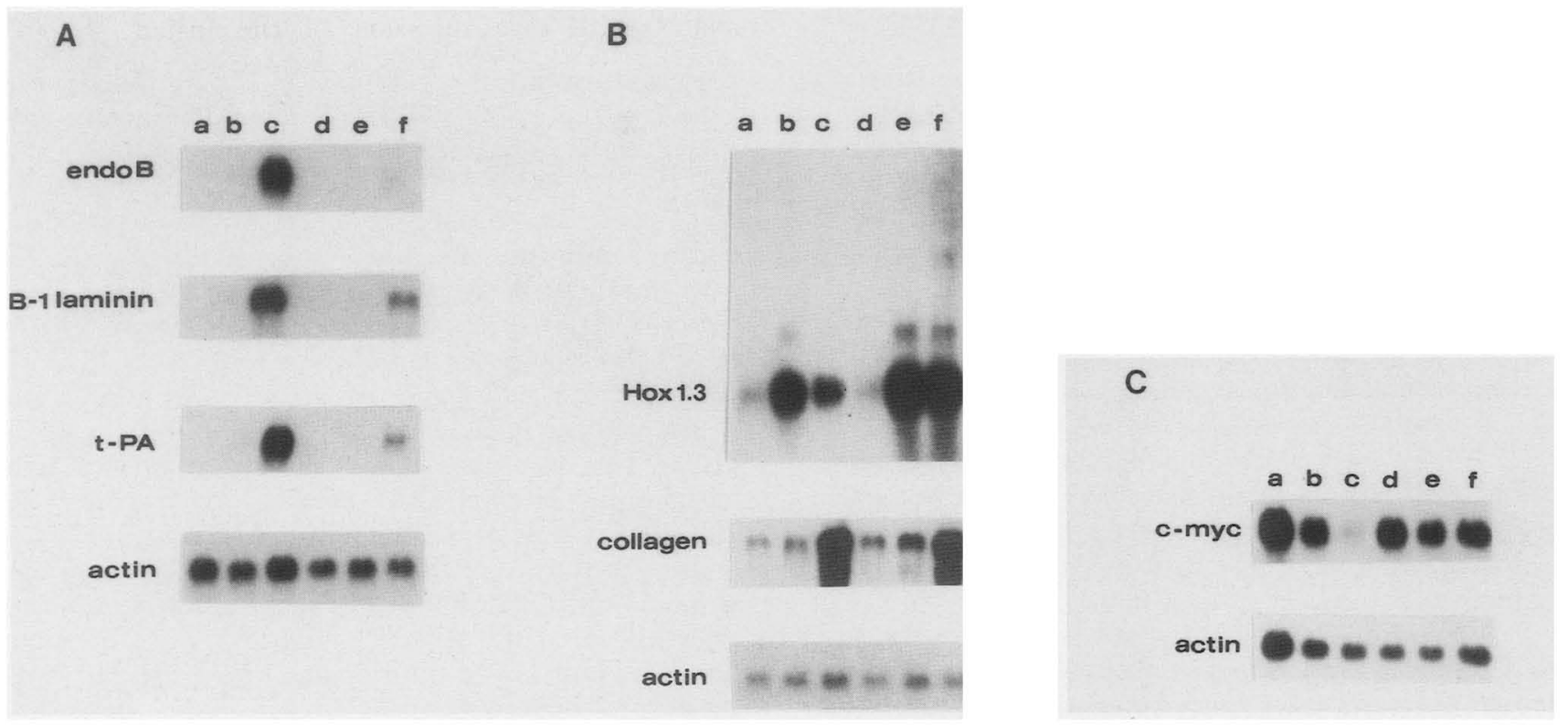

Figure 5. Northern gel analysis of poly $(A)^{+}$RNA from F9 cells and mixed clones of SAC RAR-CB-expressing F9 cells that were selected for G418 resistance and retinoic acid resistance. Six micrograms of poly(A)+ RNA was run per lane. (Lanes $a, b$, and $c)$ F9 cell RNA; 0,24 , and $72 \mathrm{hr}$ of RAC, respectively. (Lanes $d, e$, and f) SAC RAR-CB mixed clone RNA; 0,24 , and $72 \mathrm{hr}$ of RAC, respectively. Specific activity of probes and exposure times: (A) Endo B, $3.9 \times 10^{9} \mathrm{cmp} / \mu \mathrm{g}, 5 \mathrm{hr}$; B-1 laminin, $1.8 \times 10^{9} \mathrm{cpm} / \mu \mathrm{g}, 2 \mathrm{hr} ; \mathrm{t}-\mathrm{PA}$, $1.8 \times 10^{9} \mathrm{cpm} / \mu \mathrm{g}, 6 \mathrm{hr}$; $\gamma$-actin, $3.2 \times 10^{9} \mathrm{cpm} / \mu \mathrm{g}, 28 \mathrm{hr} .(B) H o x-1.3,3.2 \times 10^{9} \mathrm{cpm} / \mu \mathrm{g}, 68 \mathrm{hr}$; type IV alpha-1 collagen, $1.8 \times 10^{9}$ $\mathrm{cpm} / \mu \mathrm{g}, 10 \mathrm{hr} ; \gamma$-actin, $3.2 \times 10^{9} \mathrm{cpm} / \mu \mathrm{g}, 28 \mathrm{hr}$. $(C) \mathrm{c}-m y c, 3.9 \times 10^{9} \mathrm{cpm} / \mu \mathrm{g}, 16 \mathrm{hr} ; \gamma$-actin, $4.3 \times 10^{9} \mathrm{cpm} / \mu \mathrm{g}, 21 \mathrm{hr}$.

the defect in differentiation effect is being produced through overexpression of the fusion protein.

There are a number of genes that are differentially expressed in F9 stem cells and F9 cells treated with retinoic acid. Because overexpression of the SAC RAR-CB vector yields cells that appear to be undifferentiated EC cells, studies were performed to compare the expression of some retinoic acid-responsive genes in these clones compared with normal F9 EC cells. Endo B (Singer et al. 1986), t-PA (Rickles et al. 1988), B-1 laminin (Wang and Gudas 1983), and type IV collagen [alpha-2 (Wang and Gudas 1983); alpha-1 (Rickles et al. 1988)] are transcriptionally induced to high levels of expression within 48-72 $\mathrm{hr}$ after addition of retinoic acid plus dibutyryl cAMP to F9 cells. Conversely, the level of c-myc mRNA decreases dramatically within $8 \mathrm{hr}$ of retinoic acid administration to F9 cells (Campisi et al. 1984; Dony et al. 1985).

Northern analysis was performed on poly $(\mathrm{A})^{+}$RNA extracted from mixed clones of SAC RAR-CB-expressing, retinoic acid-resistant $\mathrm{F} 9$ cells, and normal F9 cells cultured in $0.5 \mu \mathrm{M}$ retinoic acid/1.0 mM dibutyryl cAMP (RAC) for 0,24 , and $72 \mathrm{hr}$. The results are shown in Figure 5. F9 cells and SAC RAR-CB cells express low to undetectable levels of the cytokeratin gene endo $B$ (Fig. 5A, lanes a and d); this RNA increases dramatically in F9 cells treated for $72 \mathrm{hr}$ with RAC (Fig. 5A, lane c). However, after $72 \mathrm{hr}$ in RAC, the SAC RAR-CB clones express greatly reduced levels of endo $B$ mRNA, relative to normal RAC-treated, F9 cells (Fig. 5A, lane f). Densitometric analysis was performed on linear range expo- sures, and the signals were normalized against $\gamma$-actin levels to control for differences in the amount of RNA among lanes. This analysis reveals that SAC RAR-CB clones express 36 -fold less endo $B$ mRNA than normal F9 cells treated for $72 \mathrm{hr}$ with RAC. The same pattern was observed for B-1 laminin and t-PA. Both genes are expressed at low to undetectable levels in F9 EC cells and SAC RAR-CB clones not treated with RAC (Fig. 5A, lane a and d). However, by $72 \mathrm{hr}, \mathrm{B}-1$ laminin and t-PA are expressed at 12- to 14- and 30-fold lower levels, respectively, in SAC RAR-CB clones compared with normal F9 cells.

Different results were obtained with type IV alpha-1 collagen expression. Type IV collagen is expressed at low levels in F9 stem cells (Fig. 5B, lane a) and is induced to high levels by $72 \mathrm{hr}$ in RAC ( $24 \mathrm{hr}$ RAC, lane b; $72 \mathrm{hr}$ RAC, lane c). SAC RAR-CB clones have an identical pattern of type IV alpha-1 collagen mRNA synthesis, compared with normal $F 9$ cells (uninduced, lane d; $24 \mathrm{hr}$ $\mathrm{RAC}$, lane e; $72 \mathrm{hr}$ RAC, lane f). In addition, when RNA was examined from $H o x-1.3$, a gene that is retinoic acidinduced rapidly in F9 cells (Fibi et al. 1988; Murphy et al. 1988), a retinoic acid induction is still observed in the SAC RAR-CB cells [Fig. 5B, F9 cells uninduced (lane a); $24 \mathrm{hr}$ RAC (lane b); $72 \mathrm{hr}$ RAC (lane c); SAC RAR-CB cells, uninduced (land d); $24 \mathrm{hr}$ RAC (lane e); $72 \mathrm{hr}$ RAC (lane f)]. These results suggest that both type IV alpha-1 collagen and Hox-1.3 are regulated by different pathways than either endo B, B-1 laminin, or t-PA. They also suggest that the SAC RAR-CB vector is only affecting part of the retinoic acid induction pathways. 
c-myc gene expression was used as a marker for undifferentiated F9 EC cells. It is expressed in F9 EC cells (Campisi et al. 1984), but mRNA levels drop after administration of retinoic acid (Campisi et al. 1984; Dony et al. 1985). c-myc levels in F9 cells drop to almost undetectable levels by $72 \mathrm{hr}$ of RAC (Fig. 5C, lane c); however, in SAC RAR-CB cells, c-myc levels remain high [they drop only two- to threefold by $72 \mathrm{hr}$ of RAC (Fig. 5C, lane f)].

Similar Northern analysis results were obtained with all of the above probes when specific SAC RAR-CB clones, rather than mixed clones, were analyzed. Therefore, by mRNA expression criteria and by morphology (Fig. 3) the clones appear to be EC cells. However, they are EC cells in which the retinoic acid differentiation process is inhibited and which no longer produce the normal retinoic acid induction of t-PA, endo $\mathrm{B}$, and $\mathrm{B} 1$ laminin mRNAs.

To further characterize the molecular phenotype and to determine whether overexpression of the fusion protein might be affecting gene expression directly, a series of transient transfections were performed (Table 2). Umesono et al. (1988) have demonstrated that the RARalpha functionally responds to DNA sequences to which the thyroid receptor binds (TRE sequences). In transient transfection assays utilizing a CAT construct containing the TRE fused to the herpes simplex virus (HSV) thymidine kinase promoter, F9 cells treated with retinoic acid exhibited a markedly higher level of CAT activity relative to those not treated.

Table 2. Transfection of F9 EC cells and SAC RAR-CB clones with a TRE/TKpr/Luciferase construct

\begin{tabular}{|c|c|c|c|c|c|c|}
\hline \multirow[b]{3}{*}{ Cells } & \multicolumn{6}{|c|}{ Relative luciferase activity } \\
\hline & \multicolumn{3}{|c|}{$\begin{array}{c}\text { experiment } \\
\text { without SEAP }\end{array}$} & \multicolumn{3}{|c|}{$\begin{array}{l}\text { experiment } \\
\text { with SEAP }\end{array}$} \\
\hline & 1 & 2 & 3 & 4 & 5 & 6 \\
\hline F9 EC & 1.0 & 1.0 & 1.0 & 1.0 & 1.0 & 1.0 \\
\hline $\mathrm{F} 9+\mathrm{RA}$ & 8.6 & 8.0 & 7.0 & 8.0 & 12.4 & 14.4 \\
\hline $\begin{array}{l}\text { SAC RAR-CB } \\
\text { clone H } \\
\text { SAC RAR-CB }\end{array}$ & 1.0 & 1.0 & 1.0 & 1.0 & 1.0 & 1.0 \\
\hline clone $\mathrm{H}+\mathrm{RA}$ & 3.2 & 3.6 & 2.8 & 1.1 & 4.0 & 1.5 \\
\hline $\begin{array}{l}\text { SAC RAR-CB } \\
\text { clone } 2 \\
\text { SAC RAR-CB }\end{array}$ & - & - & - & - & - & 1.0 \\
\hline clone $2+\mathrm{RA}$ & - & - & - & - & - & 0.6 \\
\hline
\end{tabular}

In experiments $1-3$ the cells were transfected with $20 \mu \mathrm{g}$ of TRE/TKpr/Luciferase/10-cm plate. The relative luciferase activity for experiments $1-3$ was determined by dividing the specific activity of luciferase from the transfected plate by the specific activity of luciferase for transfected, nonretinoic acidtreated F9 cells. For experiments $4-6,20 \mu \mathrm{g}$ of an RSV-SEAP plasmid was cotransfected with $20 \mu \mathrm{g}$ of the TRE/TKpr/Luciferase plasmid. The specific activity of luciferase was divided by the activity of SEAP from the same plate. For relative luciferase activity, the above calculated figure was divided by the value obtained for nonretinoic acid-treated F9 cells.
To examine whether expression of the SAC RAR-CB fusion protein might interfere with TRE-mediated retinoic acid induction, a plasmid containing a luciferase gene fused to a single TRE and thymidine kinase promoter was constructed (TRE/TKpr/Luciferase). F9 cells and two F9 RAR SAC-CB-expressing clones (clones $\mathrm{H}$ and 2) were transfected with this recombinant and then cultured in the presence and absence of retinoic acid. As a control for variations in transfection efficiency, a Rous sarcoma virus-secreted alkaline phosphatase (RSVSEAP) plasmid was cotransfected in some cases. In these cotransfections, the luciferase activity was normalized to secreted alkaline phosphatase activity from the same plates. The data from several transfections, with and without the internal SEAP control, are illustrated in Table 2. Retinoic acid induction of luciferase is always reduced in the SAC RAR-CB clones. The variability observed is most probably due to slight differences in the growth state of the cells from transfection to transfection. The human $\beta$-actin promoter may be sensitive to these differences, which would result in different levels of SAC RAR-CB fusion protein. This might explain, at least in part, why a complete inhibition of retinoic acid induction of luciferase is not always observed; alternatively, this could be due to the presence of other RARs, not inhibited by the SAC RAR-CB fusion protein. This would be consistent with the results discussed above, indicating that a retinoic acid inducibility of type IV alpha-1 collagen and Hox-1.3 is still obtained in the clones.

\section{Discussion}

This report has documented how a selected region of the human RAR-alpha, when overexpressed, can inhibit retinoic acid-induced differentiation of F9 EC cells. The use of the pHbetaApr-1 neo-CB-17 vector of Figure 1 has facilitated our work, as it allows easy identification of expressing clones by in situ staining and quantitation of the fusion protein with commercially available monoclonal antibodies to $\beta$-galactosidase. Using this vector, high expression of the SAC RAR-CB fusion protein has been correlated via Western analysis with the inability of F9 cells to differentiate in the presence of retinoic acid. When specific genes were examined to confirm the molecular phenotype of the SAC RAR-CB-expressing cells, the pattern of expression one would expect from normal undifferentiated F9 cells was obtained in all cases. However, when SAC RAR-CB cells were retinoic acid-treated and their RNAs examined, the observed gene expression fell into two patterns: (1) Endo B, laminin B-1, and t-PA RNAs were not markedly retinoic acid-induced, and c-myc RNA levels did not decrease significantly, as is characteristic of undifferentiated, nonretinoic acid-induced F9 EC cells; and (2) type IV alpha-1 collagen and Hox-1.3 RNAs were retinoic acidinduced, indicating patterns characteristic of retinoic acid-induced F9 EC cells. In addition, transfection of F9 cells and SAC RAR-CB-expressing clones with a TRE/ $\mathrm{TKpr} /$ Luciferase construct in the presence and absence 
of retinoic acid (Table 2) results in inhibition of retinoic acid induction of luciferase in the SAC RAR-CB-expressing clones. The overexpression of the SAC RAR-CB fusion protein (1) inhibits differentiation of F9 cells; (2) inhibits the retinoic acid regulation of endo $B$, laminin B-1, tissue plasminogen activator, and c- $m y c_{\text {; }}(3)$ inhibits the responsiveness of the cells to TRE sequences; and (4) does not affect the regulation of type IV alpha-1 collagen and Hox-1.3. Therefore, the vector appears to be working with some specificity.

For mouse RARs, it has been shown that mRAR-alpha and mRAR-gamma RNAs are expressed in undifferentiated and retinoic acid-induced F9 cells, whereas mRAR-beta RNA is induced by retinoic acid (Zelent et al. 1989|. There is a very strong conservation of amino acid sequences between hRAR-alpha and mRAR-alpha, which suggests that results similar to those described in this study would have been obtained had mRAR-alpha sequences been used instead of hRAR-alpha sequences. The divergence of amino sequence among the three mouse RARs is strongest in the A and F domains of the receptors. Preliminary observations indicate that the vector is working in a specific manner because - $\mathrm{CB}$ fusion proteins expressing either specific subfragments of the SAC RAR insert or all but the carboxy-terminal 14 amino acids do not give us this dominant-negative effect (E. Linney and A. Espeseth, unpubl.). Results with a protein product of an alternatively spliced c-erbA mRNA (Koenig et al. 1989) and with v-erbA protein (Damm et al. 1989) suggest that dominant-negative effects resembling observations with the SAC RAR-CB vector are occurring naturally. Koenig et al. (1989) have shown that thyroid hormone action is inhibited by a nonhormonebinding, c-erbA protein produced through alternative splicing. This new product binds DNA but does not bind T3. Damm et al. (1989) recently reported that the protein encoded by v-erbA acts as a thyroid hormone receptor antagonist; the DNA-binding domain of v-erbA was required for this effect, although the mechanism by which it was acting remains to be discovered. In both of these cases, the dominant-negative effect was produced by a protein that did not have a functional ligandbinding domain, a situation similar to the SAC RAR-CB protein in this study. Therefore, the mechanisms by which these results are effected may be similar for all three situations.

Given that mRAR-alpha and mRAR-gamma RNAs are expressed in undifferentiated F9 cells (Zelent et al. 1989|, one interpretation of the differentiation inhibition produced by the SAC RAR-CB vector is that the action of mRAR-alpha and mRAR-gamma receptors is being inhibited and either one or both receptors are required, directly or indirectly, for retinoic acid-induced differentiation of F9 cells. Implicit in this interpretation would be that the retinoic acid induction of the type IV alpha-1 collagen and Hox-1.3 genes would not be mediated through either of these receptors. Alternatively, the SAC RAR-CB vector may be specifically inhibiting the mRAR-alpha, and proper functioning of this receptor is required for retinoic acid-induced differentiation of $\mathrm{F9}$ cells. This would provide the possibility that the type IV alpha- 1 collagen and $H o x-1.3$ genes might be regulated by either the mRAR-gamma and/or mRAR-beta receptors. An alternative possibility-that different thresholds of RARs may be required for the regulation of different genes-is less likely, based on Northern analysis of mixed clones (illustrated in Fig. 5) and single clones (S. Murphy, unpubl.). In either case, results similar to the data illustrated in Figure 5 are obtained. If there were different threshold levels of a particular RAR required for different genes, Northern analysis of RNA from mixed clones versus individual clones would most probably yield different results. These possibilities can be examined through the construction and examination of SAC RAR-CB-like vectors for mRAR-gamma and mRAR-beta.

The specific mechanism by which the dominant-negative effect is obtained remains to be shown. Three distinct and testable possibilities might explain the mechanism: (1) The SAC RAR-CB protein cannot transcriptionally activate retinoic acid-inducible or -repressible genes but can compete effectively for mRAR DNAbinding sites; (2) the mRAR(s) must dimerize to functionally bind to specific DNA-binding sites [as has been suggested for steroid hormone receptors (Kumar and Chambon 1988; Tsai et al. 1988; Klein-Hitpass et al. 1989)], and the SAC RAR-CB fusion protein is dimerizing with endogenous receptors and functionally inactivating them; or (3) the overexpression of the $\mathrm{A} / \mathrm{B}$ domain of the SAC RAR-CB fusion protein is competing for factors required for the proper functioning of endogenous mRAR(s) [as has been suggested for the $\mathrm{A} / \mathrm{B}$ domain of the estrogen receptor (Meyer et al. 1989)]. These possibilities can be examined through a combination of domain mapping of the SAC RAR-CB vector to identify what sequences are necessary for this dominant-negative effect, and through in vitro DNA-binding studies with the hRAR-alpha and SAC RAR-CB fusion proteins. The baculovirus virus expression system has recently been modified using the - $\mathrm{CB}$ cassette, thus allowing the identification and isolation of various domains of the hRAR-alpha receptor for DNA binding and in vitro competition binding experiments.

Although several questions remain concerning the mechanism and specificity of these vectors, these results are, to our knowledge, the first study functionally implicating the RARs in a differentiation event. Given these observations, it would be of interest to examine whether vectors of this kind could be targeted through tissue-specific promoters at developmental times and in tissues that are known to be sensitive to retinoids. Transgenic mouse studies are currently under way to address these questions.

\section{Materials and methods}

Cell culture

F9 cells were grown as described previously (Linney and Donerly 1983 ). 


\section{Recombinant DNA constructs}

The basic transfection vector used, pHbetaApr-1 neo /Gunning et al. 1987), has a SVNEO cassette for G418 selection and the human $\beta$-actin promoter for expression of the RAR fragments. This vector has unique HindIII and BamHI sites $3^{\prime}$ to the $\beta$ actin promoter. For making the collagen linker/ $\beta$-galactosidase fusion vector, an EcoRI site in $L a c Y, 3^{\prime}$ to $L a c Z$ of plasmid pDS100 (Moskaluk and Bastia 1987) was modified to a BgIII site with an adaptor oligonucleotide. This created a $\mathrm{BamHI} / \mathrm{col}$ lagen linker $\beta$-galactosidase $/ B g$ III fragment, which was cloned into the BamHI site of pHbetaApr-l neo. This created plasmid pHbetaApr-1 neo-CB-17 (see Fig. 1), maintaining a unique HindIII and BamHI site between the $\beta$-actin promoter and the collagen linker $\beta$-galactosidase (-CB)-coding region. For the two recombinants described in Figure 2, the RAR-alpha sequences were modified with the following adaptor oligonucleotides: (1) SAC RAR-CB, a SacI fragment from plasmid pKHI /Giguere et al. 1987) was modified with a $7-\operatorname{mer}\left(5^{\prime}\right.$-CATTGAG-3') and a 15-mer $\left(5^{\prime}\right.$-GATCCTCAATGAGCT-3'), subcloned and then cloned into pHbetaApr-1-neo-CB-17; (2) SAC RAR-STOP, the $B a m H I$ insert from the SAC RAR-CB vector described above was modified to have a translational stop signal and HindIII ends with a 15-mer $\left(5^{\prime}\right.$-GATCCCTAAGCTTGG-3') and an 11mer $\left(5^{\prime}\right.$-CCAAGCTTAGG-3'). After subcloning, this insert was cloned into the HindIII site of the pHbetaApr-1 neo vector. The two vectors had 189 amino acids of the hRAR-alpha-coding sequence.

The thymidine kinase/luciferase construct was generously provided by S. Langer and M. Ostrowski. The TRE/TKpr/Luciferase construct was constructed by inserting the following self-hybridizing oligonucleotide $15^{\prime}$-GATCAGGTCATGACCT$\left.3^{\prime}\right)$ containing TRE sequences into a BglII site just 5 ' to the HSV thymidine kinase promoter. The luciferase cDNA (DeWet et al. 1987) included the luciferase poly(A) signal. The RSV long terminal repeat SEAP vector was generously provided by B. Cullen (Berger et al. 1988).

\section{Transfection, selection, and assays of cells}

For selection of stable transformants from the SAC RAR-CB and SAC RAR-STOP vectors, all plasmids used were banded twice in $\mathrm{CsCl} / \mathrm{EtBr}$ gradients. Concentration of plasmid DNA was determined both spectrophotometrically and through examination of dilutions of each plasmid run on $1 \%$ agarose gels. In each experiment, at least four plates of cells were transfected per DNA being examined. Cells were plated at $3.5 \times 10^{5} / 10-\mathrm{cm}$ gelatinized plate, transfected the next day with $20 \mu \mathrm{g} /$ plate of calcium phosphate precipitates, and selected with $800 \mu \mathrm{g} / \mathrm{ml}$ G418 2 days after transfection (for transfection details, see Linney and Donerly 1983). Two days after the first administration of $\mathrm{G} 418,5 \times 10^{-7} \mathrm{M}$ retinoic acid was added to at least two plates. For analysis of clones produced and clones staining for $\beta$-galactosidase activity, 2 weeks after G418 selection with or without retinoic acid selection, cells were washed twice with phosphate buffered saline |PBS|, fixed with $2 \%$ paraformaldehyde $-0.2 \%$ gluteraldehyde in PBS at $4^{\circ} \mathrm{C}$ for $15 \mathrm{~min}$, washed with PBS and stained for $\beta$-galactosidase activity at $37^{\circ} \mathrm{C}\left[0.02 \% \mathrm{NP}-40,0.01 \%\right.$ sodium deoxycholate, $2 \mathrm{mM} \mathrm{MgCl}_{2}$, $5 \mathrm{~mm}$ potassium ferrocyanide, $5 \mathrm{~mm}$ potassium ferricyanide, 1 $\mathrm{mg} / \mathrm{ml}$ of 4 -chloro-5-bromo-3-indolyl- $\beta$-galactosidase (X-gal) in PBS]. The stocks of cells selected for G418 resistance were maintained under G418 selection.

Cells transfected with luciferase plasmids were washed twice with ice-cold PBS and scraped off the plates into $1.0 \mathrm{ml}$ of 100 mM potassium phosphate ( $\mathrm{pH} 7.8$ )/1 mM dithiothreiotol (DTT).
Cells were transferred to 1.5-ml Eppendorf tubes and centrifuged for $2 \mathrm{~min}$ at $4000 \mathrm{rpm}$ and $4^{\circ} \mathrm{C}$. Pellets were resuspended in $100 \mu \mathrm{l}$ of $100 \mathrm{~mm}$ potassium phosphate $(\mathrm{pH} 7.8) / 1 \mathrm{~mm}$ DTT and lysed by freeze/thawing three times. The samples were then centrifuged for $5 \mathrm{~min}$ at $12,000 \mathrm{rpm}$ and $4^{\circ} \mathrm{C}$, and the supernatant was collected to measure luciferase activity.

The activities were measured using 10-30 $\mu$ l extract. Aliquots were mixed with $350 \mu \mathrm{l}$ of a buffer containing $2.5 \mathrm{~mm}$ glycylglycine (pH 7.8), $20 \mathrm{mM}$ ATP, $15 \mathrm{~mm} \mathrm{MgSO}_{4}, 0.5 \mathrm{~mm}$ DTT, and $200 \mu \mathrm{g} / \mathrm{ml}$ bovine serum albumin (fraction V). The peak of luciferase activity was measured for 10 -sec intervals at $25^{\circ} \mathrm{C}$, using a Berthold model LB9500C luminometer. D-luciferin (Sigma), the substrate for luciferase, was added in $100-\mu \mathrm{l}$ aliquots at a concentration of $0.5 \mathrm{~mm}$. Protein concentrations were normalized using a Bradford microtiter assay (Bradford 1976).

\section{RNA isolation}

Poly $(\mathrm{A})+$ RNA was isolated as described by Vennstrom and Bishop (1982). Cells were washed twice with ice-cold PBS and scraped off the plates into ice-cold STE $(100 \mathrm{mM} \mathrm{NaCl}, 20 \mathrm{mM}$ Tris at $\mathrm{pH} 7.4,10 \mathrm{~mm}$ EDTA). The suspension was transferred to a Thomas $\mathrm{C} 134$ homogenizing tube, and proteinase $\mathrm{K}$ and SDS were added to final concentrations of $400 \mu \mathrm{g} / \mathrm{ml}$ and $0.5 \%$, respectively. The cells were disrupted for $30 \mathrm{sec}$ by stroking with the homogenizer pestle connected to an electric drill. The homogenates were incubated for $40 \mathrm{~min}$ at $37^{\circ} \mathrm{C}$, and $\mathrm{NaCl}$ was added to a final concentration of $0.5 \mathrm{M}$. Oligo(dT) (Collaborative Research type III) was added, and the mixture was shaken at room temperature for $2-24 \mathrm{hr}$. Oligo(dT) column chromatography was performed on the mixture to purify the poly $(\mathrm{A})^{+}$ RNA.

\section{RNA analysis}

Poly $(\mathrm{A}){ }^{+}$RNA was electrophoresed through $1 \%$ agarose $/ 2.2 \mathrm{M}$ formaldehyde gels as described by Maniatis et al. (1982). Gels were blotted onto nitrocellulose (Schleicher \& Schuell, BA85) in $10 \times \mathrm{SSC}$, and the filters were then vacuum-oven-baked for 2 $\mathrm{hr}$ at $80^{\circ} \mathrm{C}$. Filter hybridizations were done as described by Meinkoth and Wold (1984). Blots were prehybridized for 12-16 hr at $68^{\circ} \mathrm{C}$ in $5 \times$ SSPE, $5 \times$ Denhardt's solution, $0.1 \%$ SDS, and $100 \mu \mathrm{g} / \mathrm{ml}$ of denatured salmon sperm DNA. Random prime labeled DNA probes were prepared as described by Feinberg and Vogelstein (1983). The probes used to detect the different RNAs were (1) type IV alpha-1 collagen, a 1790-bp EcoRI-HindIII cDNA fragment from pE123 (Rickles et al. 1988); (2) t-PA, a 690-bp, 5' EcoRI cDNA fragment from $\lambda 2$ (Rickles et al. 1988); (3) c-myc, a 4.83-kbp HindIII fragment from genomic DNA MOPC 315 (Shen-Ong et al. 1982); (4) B-1 laminin, a 1.4-kbp HindIII cDNA fragment from pPE49 (Barlow et al. 1984); (5) $\gamma$ actin, a 1.58-kbp BamHI cDNA fragment from pHFI (Gunning et al. 1983); (6) endo B, a 700-bp HindIII-EcoRI cDNA fragment from pUC9B7 (Singer et al. 1986); (7) Hox-1.3, a 460-bp BamHI-BgIII cDNA fragment (probe 1 in Murphy et al. 1988). Specific activities ranged from $10^{9}$ to $6 \times 10^{9} \mathrm{cpm} / \mu \mathrm{g}$ of DNA. Blots were hybridized in the presence of $2 \times 10^{6} \mathrm{cpm} / \mathrm{ml}$ denatured probe for $18-24 \mathrm{hr}$ at $68^{\circ} \mathrm{C}$ in the same buffer used for prehybridization. Filters were washed twice at room temperature for $5 \mathrm{~min}$ in $1 \times \mathrm{SSPE} / 0.1 \% \mathrm{SDS}$ and twice at $50^{\circ} \mathrm{C}$ for 15 $\mathrm{min}$ in $0.1 \times \mathrm{SSPE} / 0.1 \%$ SDS. The filters were then subjected to autoradiography at $-70^{\circ} \mathrm{C}$ on Kodak XAR- 5 film with the use of intensifying screens. 


\section{Western blot analysis}

Protein samples were obtained from individual and mixed clone cultures by washing each plate twice with PBS, adding 0.5 $\mathrm{ml}$ lysis buffer $[0.0625 \mathrm{M}$ Tris-Cl $(\mathrm{pH} 6.8), 2 \%$ SDS, $10 \%$ glycerol, 5\% 2-mercaptoethanol (Laemmli 1970)], boiling the lysate for $5 \mathrm{~min}$, and freezing the lysate immediately in liquid nitrogen. The concentration of the protein was determined via a Bradford microtiter assay using the Bio-Rad dye reagent (Bradford 1976). The samples were run on $5 \%$ polyacrylamide gels (Laemmli 1970) overnight at $8 \mathrm{~mA}$. The gels were then soaked in Towbin's buffer [25 mM Tris (pH 8.3), $192 \mathrm{~mm}$ glycine, $20 \%$ methanol (vol/vol) (Towbin et al. 1979)] for $1 \mathrm{hr}$ and blotted onto nitrocellulose for $8 \mathrm{hr}$ at full power (1-1.5 mA), using a Hoefer Scientific Instruments Transphor (TE 42) transfer electrophoresis unit in the same buffer (Towbin et al. 1979; Burnette 1981). The nitrocellulose filters were incubated in TBST [25 mM Tris, $136 \mathrm{~mm} \mathrm{NaCl}, 5 \mathrm{mM} \mathrm{KCl}, 7 \mathrm{~mm} \mathrm{Na} \mathrm{HPO}_{4}$ (pH 7.4), $5.5 \mathrm{~mm}$ dextrose, $0.05 \%$ Tween 20 ] with $1 \%$ (wt/vol) powdered milk as a blocking buffer for $30 \mathrm{~min}$ and shaking at room temperature. The primary antibody (anti- $\beta$-galactosidase obtained from Promega) was added in blocking buffer and allowed to bind for $1 \mathrm{hr}$. The filter was then washed three times with TBST. The secondary antibody was an anti-mouse IgG $(\mathrm{H}+\mathrm{L})$ alkaline phosphatase conjugate from the Promega ProtoBlot Immunoblotting System, which was allowed to bind for $1 \mathrm{hr}$ under the same conditions as the primary antibody and was also washed three times with TBST. A reaction buffer was prepared to visualize the conjugated alkaline phosphatase: $33 \mu$ l NBT (50 $\mathrm{mg} / \mathrm{ml}$ nitro blue tetrazolium in $70 \%$ dimethylformamide; Promega) was added to $5 \mathrm{ml} \mathrm{AP}$ buffer [ $100 \mathrm{~mm}$ Tris- $\mathrm{HCl}$ (pH 9.5), $100 \mathrm{mM} \mathrm{NaCl}, 5 \mathrm{~mm} \mathrm{MgCl}$, mixed, and following this, $16.5 \mu \mathrm{l}$ BCIP $150 \mathrm{mg} / \mathrm{ml} 5$-bromo-4-chloro-3-indolyl-phosphate in dimethylformamide; Promega) was added to this solution and mixed (Blake et al. 1984). Two sheets of Whatman No. 1 paper wetted with AP buffer were used to sandwich the nitrocellulose filter to minimize background. The reaction buffer was then poured directly onto the filter sandwich and allowed to develop at room temperature in the dark for $4 \mathrm{hr}$. The solution was then poured off and the filter was allowed to dry overnight at room temperature.

\section{Acknowledgments}

We thank V. Giguere and R. Evans for providing us with the cDNA to the hRAR-alpha, without which we would not have been able to initiate these studies; C. Moskaluk and D. Bastia for the collagen linker/ $\beta$-galactosidase cassette; R. Oshima for the endo B probe; S. Strickland for the t-PA and type IV alpha-1 collagen probes; M. Ostrowski and S. Langer for the TK-luciferase plasmid and advice on optimizing use of it; D. Prestridge and B. Kelley for advice on Western blot analysis; B. Cullen for the RSV-SEAP plasmid, and B. Hanna for aid in typing the manuscript. A. Espeseth is a member of the cell and Molecular Biology Program (GM07184) and is supported by a National Science Foundation predoctoral fellowship. This research has been supported by National Institutes of Health grants CA39066 and HD24130 and a North Carolina Biotechnology grant.

\section{References}

Barlow, D., N.M. Green, M. Kurkinen, and B.L.M. Hogen. 1984. Sequencing of laminin B chain cDNAs reveals C-terminal regions of coiled-coil alpha-helix. EMBO $I$. 3: 2355-2362.
Benbrook, D., E. Lernhardt, and M. Pfahl. 1988. A new retinoic acid receptor identified from a hepatocellular carcinoma. Nature 333: 669-672.

Berger, J., J. Hauber, R. Hauber, R. Geiger, and B.R. Cullen. 1988. Secreted placental alkaline phosphatase: A powerful new quantitative indicator of gene expression in eukaryotic cells. Gene 66: 1-10.

Blake, M.S., K.H. Johnston, G.J. Russell-Jones, and E.C. Gotschlich. 1984. A rapid, sensitive method for detection of alkaline phosphatase-conjugated anti-antibody on Western blots. Anal. Biochem 136: 175-179.

Bradford, M.M. 1976. A rapid and sensitive method for the quantitation of microgram quantities of protein utilizing the principle of protein-dye binding. Anal. Biochem. 72: 248254.

Brand, N., M. Petkovich, A. Krust, P. Chambon, H. de The, A. Marchio, P. Tiollais, and A. DeJean. 1988. Identification of a second human retinoic acid receptor. Nature 332: 850-853.

Burnette, W.N. 1981. 'Western blotting': Electrophoretic transfer of proteins from sodium dodecyl sulfate-polyacrylamide gels to unmodified nitrocellulose and radiographic detection with antibody and radioiodinated protein A. Anal. Biochem. 112: 195-203.

Campisi, J., H.E. Gray, A.B. Pardee, M. Dean, and G.E. Sonensheim. 1984. Cell-cycle control of c-myc but not c-ras expression lost following chemical transformation. Cell 36: $241-247$.

Damm, K., C.C. Thompson, and R.M. Evans. 1989. Protein encoded by v-erbA functions as a thyroid-hormone receptor antagonist. Nature 339: 593-597.

de The," H., A. Marchio, P. Tiollais, and A. Dejean. 1987. A novel steroid thyroid hormone receptor-related gene inappropriately expressed in human hepatocellular carcinoma. Nature 330: 667-670.

DeWet, J., K. Wood, M. Deluca, D. Helinski, and S. Subramani. 1987. Firefly luciferase gene: Structure and expression in mammalian cells. Mol. Cell. Biol. 7: 787-795.

Dony, C., M. Kessel, and P. Gruss. 1985. Post-transcriptional control of myc and p53 expression during differentiation of the embryonal carcinoma cell line F9. Nature 317: 636-639.

Evans, R.M. 1988. The steroid and thyroid hormone receptor superfamily. Science 240: 889-895.

Feinberg, A. and B. Vogelstein. 1983. A technique for radiolabeling DNA restriction endonuclease fragments to high specific activity. Anal. Biochem. 132: 6-13.

Fibi, M., B. Zink, M. Kessel, A.M. Colberg-Poley, S. Labeit, H. Lehrach, and P. Gruss. 1988. Coding sequence and expression of the homeo box gene Hox 1.3. Development 102: 349-359.

Germino, J. and D. Bastia. 1984. Rapid purification of a cloned gene product by genetic fusion and site-directed proteolysis. Proc. Natl. Acad. Sci. 81: 4692-4696.

Giguere, V., E.S. Ong, P. Segui, and R.M. Evans. 1987. Identification of a receptor for the morphogen retinoic acid. Nature 330: 624-629.

Godowski, P.J., D. Picard, and K.R. Yamamoto. 1988. Signal transduction and transcriptional regulation by glucocortocoid receptor-lexA fusion proteins. Science 241: 812-816.

Godowski, P.J., S. Rusconi, R. Meisfeld, and K.R. Yamamoto. 1987. Glucocortocoid receptor mutants that are consitutive activators of transcriptional enhancement. Nature 325: $365-368$.

Gronemeyer, H., B. Turcotte, C. Quirin-Stricker, M.T. Bocquel, M.E. Meyer, Z. Krozowski, J.M. Jeltsch, T. Lerouge, J.M. Garnier, and P. Chambon. 1987. The chicken progesterone 
receptor: Sequence, expression, and functional analysis. EMBO J. 60: 3985-3994.

Gunning, P., P. Ponte, H. Okayama, J. Engel, H. Blau, and L. Kedes. 1983. Isolation and characterization of full-length cDNA clones for human alpha-, beta-, and gamma-actin mRNAs: Skeletal but not cytoplasmic actins have an amino-terminal cysteine that is subsequently removed. Mol. Cell. Biol. 3: 787-795.

Gunning, P., J. Leavitt, G. Muscat, S.-Y. Ng, and L. Kedes. 1987. A human beta-actin expression vector system directs highlevel accumulation of antisense transcripts. Proc. Natl. Acad. Sci. 84: 4831-4835.

Herskowitz, I. 1987. Functional inactivation of genes by dominant negative mutations. Nature 329: 219-222.

Hollenberg, S.M. and R.M. Evans. 1988. Multiple and cooperative trans-activation domains of the human glucocortocoid receptor. Cell 55: 899-906.

Hollenberg, S.M., V. Giguere, P. Segui, and R.M. Evans. 1987. Colocalization of DNA-binding and transcriptional activation function in the human glucocortocoid receptor. Cell 49: 39-46.

Klein-Hitpass, L., S.Y. Tsai, G.L. Greene, J.H. Clark, M.-J. Tsai, and B.W. O'Malley. 1989. Specific binding of estrogen receptor to the estrogen response element. Mol. Cell. Biol. 9: 43-49.

Koenig, R.J., M.A. Lazar, R.A. Hodin, G.A. Brent, P.R. Larsen, W.W. Chin, and D.D. Moore. 1989. Inhibition of thyroid hormone action by a non-hormone binding c-erbA protein generated by alternative mRNA splicing. Nature 337: 659661.

Kumar, V. and P. Chambon. 1988. The estrogen receptor binds tightly to its responsive element as a ligand-induced homodimer. Cell 55: 145-156.

Kumar, V., S. Green, G. Stack, M. Berry, J.-R. Jin, and P. Chambon. 1987. Functional domains of the human estrogen receptor. Cell 51: 941-951.

Laemmli, U.K. 1970. Cleavage of structural proteins during the assembly of the head of bacteriophage T4. Nature 227: 680685.

Linney, E. and S. Donerly. 1983. DNA fragments from F9 PyEC mutants increase expression of heterologous genes in transfected F9 cells. Cell 35: 693-699.

Maniatis, T., E.F. Fritsch, and J. Sambrook. 1982. Molecular cloning: A laboratory manual. Cold Spring Harbor Laboratory, Cold Spring Harbor, New York.

Meinkoth, J. and G. Wahl. 1984. Hybridization of nucleic acids immobilized on solid supports. Anal. Biochem. 138: $267-$ 284.

Meyer, M.-E., H. Gronemeyer, B. Turcotte, M.-T. Bocquel, D. Tasset, and P. Chambon. 1989. Steroid receptors compete for factors that mediate their enhancer function. Cell 57: 433-442.

Moskaluk, C. and D. Bastia. 1987. The E2 'gene' of bovine papillomavirus encodes an enhancer-binding protein. Proc. Natl. Acad. Sci. 84: 1215-1218.

Murphy, S.P., J. Garbern, W.F. Odenwald, R.A. Lazzarini, and E. Linney. 1988. Differential expression of the homeobox gene Hox-1.3 in F9 embryonal carcinoma cells. Proc. Natl. Acad. Sci. 85: 5587-5591.

Nugent, J. and S. Clark. 1985. Retinoids, differentiation and disease. Ciba Found. Symp. vol. 113. Pitman Publishing, London, England.

Petkovich, M., N.J. Brand, A. Kurst, and P. Chambon. 1987. A human retinoic acid receptor which belongs to the family of nuclear receptors. Nature 330: 444-450.

Rickles, R.J., A.L. Darrow, and S. Strickland. 1988. Molecular cloning of complementary DNA to mouse tissue plasmin- ogen activator mRNA and its expression during F9 teratocarcinoma cell differentiation. J. Biol. Chem. 263: 15631569.

Shen-Ong, G., G. Keath, E. Piccoli, and M. Cole. 1982. Novel myc oncogene RNA from abortive immunoglobulin-gene recombination in mouse plasmacytomas. Cell 31: 443-452.

Sherman, M.I. 1986. Retinoids and cell differentiation. CRC press, Boca Raton.

Silver, L.M., G.R. Martin, and S. Strickland. 1983. Teratocarcinoma stem cells. Cold Spring Harbor Laboratory, Cold Spring Harbor, New York.

Singer, P.A., K. Trevor, and R.G. Oshima. 1986. Molecular cloning and characterization of the endo B cytokeratin expressed in preimplantation mouse embryos. I. Biol. Chem. 261: $538-547$.

Sporn, M.B., A.V. Roberts, and D.W. Goodman. 1984. The retinoids, vol. 2 Academic Press, New York.

Strickland, S. and V. Mahdavi. 1978. The induction of differentiation in teratocarcinoma stem cells by retinoic acid. Cell 15: 393-403.

Towbin, H., T. Staehelin, and J. Gordon. 1979. Electrophoretic transfer of proteins from polyacrylamide gels to nitrocellulose sheets: Procedure and some applications. Proc. Natl. Acad. Sci. 76: 4350-4354.

Tsai, S.Y., J. Carlstedt-Duke, N.L. Wiegel, K. Dahlman, J.-A. Gustafsson, M.-J. Tsai, and B.W. O'Malley. 1988. Molecular interactions of steriod hormone receptor with its enhancer element: Evidence for receptor dimer formation. Cell 55: $361-369$.

Umesono, K., V. Giguere, C.K. Glass, M.G. Rosenfeld, and R.M. Evans. 1988. Retinoic acid and thyroid hormone induce gene expression through a common responsive element. Nature 336: $262-265$.

Vennstrom, B. and J.M. Bishop. 1982. Isolation and characterization of chicken DNA homologous to putative oncogenes of avian erthroblastosis virus. Cell 28: 135-143.

Wang, S.-Y. and L.J. Gudas. 1983. Isolation of cDNA clones specific for collagen IV and laminin from mouse teratocarcinoma cells. Proc. Natl. Acad. Sci. 80: 5880-5884.

Webster, N.J.G., S. Green, J.R. Jin, and P. Chambon. 1988. The hormone-binding domains of the estrogen and glycocortocoid receptors contain an inducible transcription activation function. Cell 54: 199-207.

Zelent, A., A. Krust, M. Petkovich, P. Kastner, and P. Chambon. 1989. Cloning of murine alpha and beta retinoic acid receptors and a novel receptor gamma predominantly expressed in the skin. Nature 339: 714-717. 


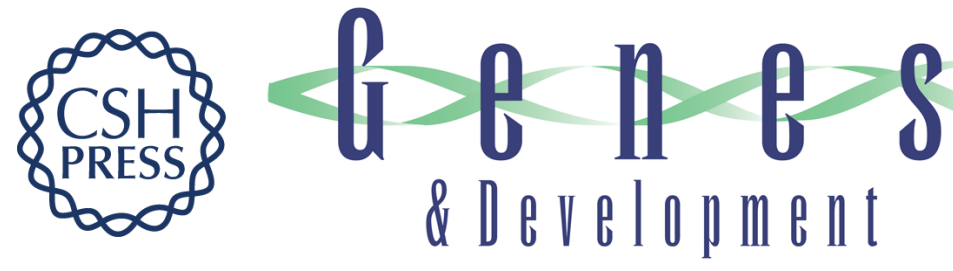

\section{Retinoic acid receptor expression vector inhibits differentiation of F9 embryonal carcinoma cells.}

A S Espeseth, S P Murphy and E Linney

Genes Dev. 1989, 3:

Access the most recent version at doi:10.1101/gad.3.11.1647

References This article cites 47 articles, 14 of which can be accessed free at:

http://genesdev.cshlp.org/content/3/11/1647.full.html\#ref-list-1

License

Email Alerting

Service

Receive free email alerts when new articles cite this article - sign up in the box at the top right corner of the article or click here.

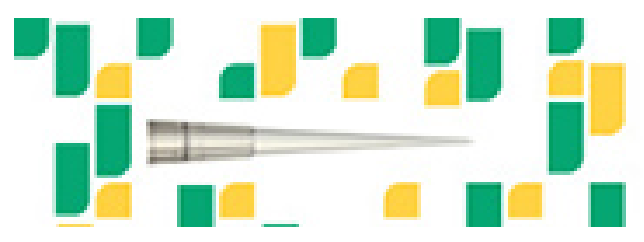

Focused on your science. 